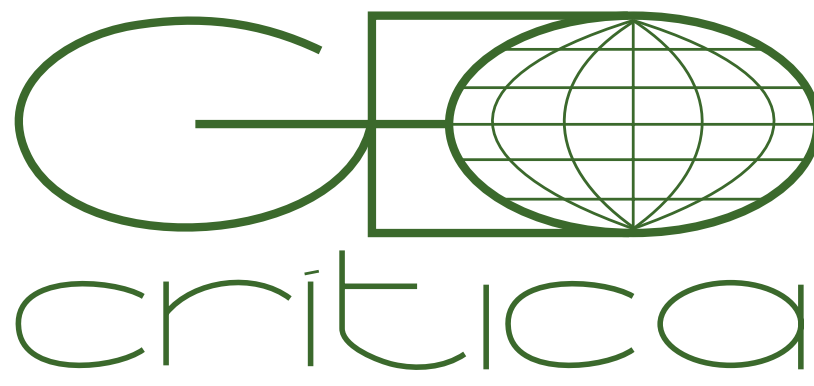

\section{Scripta Nova}

Revista Electrónica de Geografía y Ciencias Sociales Universitat de Barcelona

\title{
RESISTENCIA, PETRÓLEO Y CONFLICTO ARMADO EN LA AMAZONIA ANDINA: ANÁLISIS DESDE LA GEOGRAFÍA CRÍTICA Y LA SOCIOLOGÍA POLÍTICA DEL CONFLICTO SOCIO-AMBIENTAL DEL BLOQUE SAN JUAN
}

\author{
Juan Azuero Melo \\ Universidade Federal Rural do Rio de Janerio (CPDA -UFRRJ) \\ jf.azuero39@gmail.com
}

Recibido: 06/06/2018; Devuelto para correcciones: 29/08/2018:; Aceptado: 03/11/2018

Este artículo expone algunos resultados de la disertación presentada para obtener el título de maestro en ciencias sociales y desarrollo rural en el CPDAUFRRJ. Para la realización de esta investigación se contó con el apoyo económico del pueblo brasilero y carioca a través del CNPq y la FAPERJ. Dedicó este texto a Hector Alimonda (Q.E.P.D.) precursor de la Ecología-Política Latinoamericana, director de esta investigación y gran amigo. Agradezco a Juanita Cuellar, Francisco Azuero, Clara Melo y a los evaluadores anónimos por los aportes realizados.
Resistencia, petróleo y conflicto armado en la Amazonia Andina: análisis desde la geografía crítica y la sociología política del conflicto socio-ambiental del Bloque San Juan (Resumen)

Se analiza el conflicto socio-ambiental del Bloque San Juan (Putumayo, Colombia), entre la comunidad -representada por la Asociación Ambiental Salado de los Loros- y la petrolera Gran Tierra Energy Inc. Con el objetivo de comprender relacionalmente las perspectivas territoriales y sociopolíticas del conflicto se propone un diálogo interdisciplinar entre las corrientes teóricas del giro territorial, la sociología pragmática y la estructura de oportunidades políticas. Se concluye que nociones como restricciones y oportunidades políticas, repertorios de acción, frames- territoriales, contextos de experiencia y procesos de apropiación del espacio (territorialización), representan elementos constitutivos del conflicto en la medida en que cada una resultan fundamentales dentro de su evolución.

Palabras Clave: Putumayo, Conflicto Socio-ambiental, Giro Territorial, Estructura de Oportunidades Política, Sociología Pragmática.

\section{Resistance, oil and armed conflict in the Andean Amazon: analysis from the} critical geography and political sociology of the socio-environmental conflict of the Bloque San Juan" (Summary)

This article analyses the socio-environmental conflict of the Bloque San Juan (Putumayo, Colombia) between the local community -represented by the Asociación Ambiental El Salado de los Loros- and the oil company Gran Tierra Energy Inc. With the objective of understanding the territorial and sociopolitical perspectives of the conflict in a relational way, an interdisciplinary dialogue between the territorial turn, the pragmatic sociology and the political opportunity structure it's proposed. As a conclusion the notions of restrictions and political opportunities, repertoires of action, territorial-frames, experience contexts and processes of appropriation of space (territorialization), are presented as constitutive elements of the conflict, insofar, each one is fundamental within its evolution. Keywords: Putumayo, Socio-Environmental Conflict, Territorial Turn, Political Opportunity Structure, Pragmatic Sociology. 
El territorio conocido como Bloque San Juan (BSJ) comprende 99.836 hectáreas en la Amazonía Andina entre los municipios de Villagarzón, Orito y Puerto Caicedo, en el departamento de Putumayo (sur occidente de Colombia, ver Figura 1) ${ }^{1}$. En este territorio, que se caracteriza por altos índices de biodiversidad y gran afluencia hidrográfica, habitan alrededor de 600 familias dedicadas al cultivo de coca, caña, pimienta, chontaduro, plátano, sacha inchi y cultivos de pancoger. La mayoría son campesinos-colonos llegados a la región desde la década de 1950, que comparten el territorio con indígenas de las etnias Emberá, Inga, Nasa y Awá ${ }^{2}$ Desde principios de los años noventa esta región ha sido objeto de diversas tentativas de exploración petrolera por parte de empresas nacionales y extranjeras. Como respuesta a este fenómeno la comunidad se organizó en torno a la Asociación Ambiental El Salado de los Loros (AASL) con el propósito de negociar con las petroleras las condiciones de explotación. Sin embargo, debido a la presión de los grupos armados ilegales a mediados de la década de 1990 esta organización se desarticuló durante algunos años.

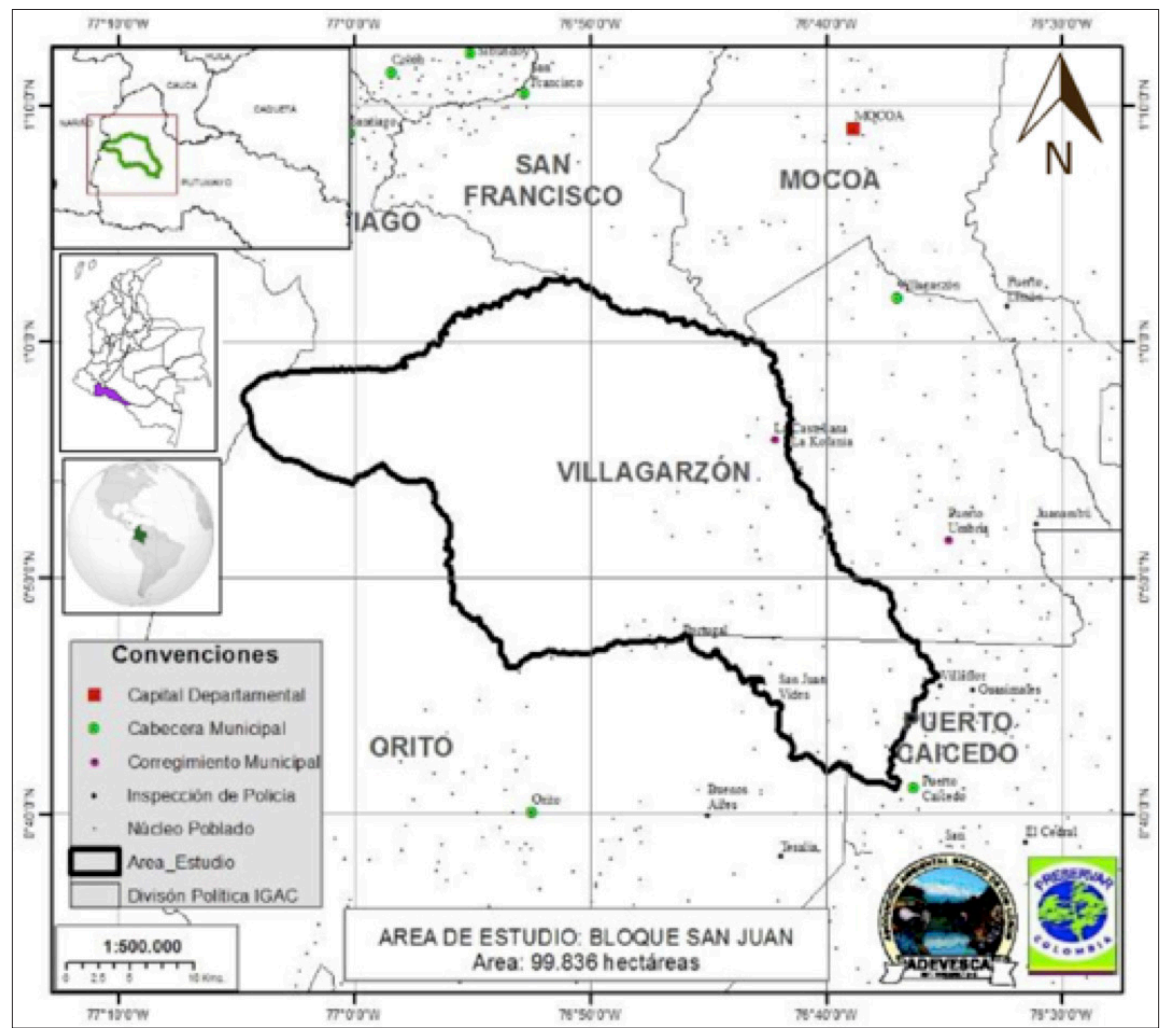

Figura 1. Mapa del Bloque San Juan Fuente: Duarte, 2016, Edición del autor.

En el 2008, luego del retorno de muchos de los habitantes que fueron desplazados la AASL vuelve a tomar fuerza en la región, solo que desde ese momento se organizan

1 Sobre la región del Bloque San Juan se conocen dos referencias que fueron un gran insumo para la investigación. Una sub-sección en el informe del Centro Nacional de Memoria Histórica de 2015, y un juicioso artículo de Margarita Chaves de 2002.

2 El término colono en el sur de Colombia hace referencia a campesinos que, expulsados de sus territorios han migrado forzosamente en busca de oportunidades y tierras. 
sobre el principio rector de proteger y velar por la preservación del ambiente y de no permitir la realización de proyectos de explotación petrolera en el área ${ }^{3}$. Esta oposición ha llevado a la configuración de un conflicto socio-ambiental entre, en una esquina, la AASL en representación de los campesinos, las etnias Nasa, Emberá, Pasto y algunos Awá, y por el otro, la empresa petrolera canadiense "Gran Tierra Energy inc.", apoyada por algunos miembros de la etnia Inga y otros Awá. La particularidad de este conflicto es que hasta el momento las estrategias empleadas por la AASL han resultado efectivas y han impedido la exploración del hidrocarburo.

El objetivo de este artículo es analizar este conflicto desde las perspectivas teóricas de la geografía crítica y la sociología política. A partir de un diálogo original entre algunos presupuestos de ciertas corrientes se analiza cómo las oportunidades y restricciones políticas, los contextos de experiencia comunales e individuales, y los procesos de territorialización, des-territorialización y re-territorialización han configurado las dinámicas y la evolución del conflicto, específicamente la (re)configuración de frames-territoriales y la elección y efectividad de ciertos repertorios de acción. De especial interés resulta examinar la trayectoria de la AASL y evidenciar cómo se ha configurado su trayectoria, que se inicia como una ONG pro-explotación de crudo hasta devenir en una organización multiétnica ambientalista cuyo rechazo al petróleo los ha llevado incluso a cometer acciones violentas como la quema de maquinaria. Lo interesante e innovador de esta propuesta teórica consiste en que muchas veces los estudios sobre conflictos y movimientos sociales dejan de lado las perspectivas territoriales y geográficas, mientras que en este se plantea una posibilidad de dialogo entre la geografía y la sociología política, específicamente entre el giro territorial, la sociología pragmática y la estructura de oportunidades políticas.

La metodología utilizada en esta investigación fue principalmente cualitativa, centrada en el trabajo de campo con la comunidad del BSJ a través de las siguientes herramientas de recolección de información: entrevistas semi-estructuradas, grupos focales, observación participante, y recorridos guiados ${ }^{4}$. La información recolectada a través de estas herramientas no solo se refirió a los productos concretos (grabaciones, diario de campo, fotografías, cartografías sociales, etc.) sino también al análisis etnográfico de tales procesos. Analizar etnográficamente los procesos de recolección de información primaria, permite además percibir "lo verbal, lo espacial, lo físico, (movimientos, bostezos, etc.), lo para-verbal (gestos, miradas, interjecciones), lo relacional, lo dramático y lo temporal", aspectos de vital importancia para esta investigación, que podrían quedar relegados mediante otras aproximaciones metodológicas ${ }^{5}$.

El artículo se organiza de la siguiente manera. Una primera sección donde se

3 En Colombia debido al conflicto armado interno la población civil, especialmente la población rural, se ha visto obligada a desplazarse forzosamente. Según La ONU, Colombia es el segundo país con mayor número de desplazados internos del mundo (5,3 millones), solo superado por Siria $(6,5)$.

4 Por seguridad e integridad física y jurídica no se usarán nombres reales.

5 Riaño 2000, p.151 
expone el marco teórico utilizado en la investigación. Una segunda, en donde se analiza el conflicto socio-ambiental del BSJ desde esa perspectiva, y que se encuentra dividida en tres subsecciones que obedecen a la temporalidad del conflicto. Y una tercera parte en la cual se presenta una breve consideración respecto a lo que este conflicto puede decirnos acerca del pos-acuerdo de paz con las Fuerzas Armadas Revolucionarios de Colombia (FARC-EP) en territorios de antigua presencia guerrillera y "ricos" en recursos naturales. Finalmente, el texto termina con unas conclusiones analíticas generales.

\section{Elementos teóricos: diálogo entre la geografía crítica y la sociología política}

En décadas pasadas, dentro de las ciencias sociales, gran parte de los análisis sobre conflictos y movimientos sociales habían sido abordados a través de marcos conceptuales cerrados, ligando la interpretación de estos procesos a referentes teóricos exclusivos e ignorando de esta forma otras interpretaciones posibles y el diálogo entre éstas. En contravía a esa tendencia, y siguiendo a Zirakdezh ${ }^{6}$-al comprender que las diferentes aproximaciones teóricas no necesariamente son incompatibles sino más bien complementarias- se propuso abordar el conflicto del BSJ considerando diferentes disciplinas y referentes teóricos, y estableciendo diálogos y combinaciones relevantes para su estudio. Al realizar esta operación se procuró que los hechos pusieran a dialogar a diferentes disciplinas a medida que se conocía el proceso, y no a través del reduccionista camino contrario de encasillar los hechos en presupuestos teóricos previos. A medida que se enfrentaban realidades que no podían ser analizadas por una sola teoría, se fueron sumando al análisis diversos referenciales teóricos, principalmente del giro territorial, de la estructura de oportunidades políticas y de la sociología pragmática.

\section{El Giro Territorial}

Se parte del principio de que la confrontación en el Bloque San Juan debe entenderse como un conflicto socio-ambiental en la medida en que es una lucha social por la apropiación del espacio, que sucede dentro del campo ambiental7. Según Acselrad, en el ámbito de las luchas sociales por apropiación del espacio, en determinadas circunstancias se constituye un campo ambiental que vincula las disputas de poder sobre el espacio y sus contenidos con un repertorio de prácticas discursivas (argumentos, valores, representaciones, causalidades, remisiones a un "orden natural" o al carácter

\footnotetext{
6 Zirakdezh, 1997.

7 De acuerdo con Bourdieu el campo se entiende como un recurso conceptual y metodológico definido como un espacio de la esfera de la vida social (económica, cultural, política, simbólica, social, ambiental etc.) donde los agentes tienen determinadas posiciones de poder y se encuentran en permanente conflicto por la hegemonía del campo, de acuerdo con ciertas reglas. Dentro de cada campo definido, los agentes apropian y acumulan diversos capitales (cultural, económico, político, ambiental, etc.). Bourdieu, 1996.
} 
benigno o dañino de prácticas espaciales, etc.), a través de las cuales los conflictos entre prácticas espaciales se ambientalizan. Estos conflictos envuelven grupos sociales con modos diferenciados de apropiación, uso y significación del espacio, que afirman que la continuidad de las prácticas espaciales que desarrollan se encuentran amenazadas por los efectos indeseables de las prácticas de otros grupos ${ }^{8}$. Así, las disputas entre actores con distintas formas de apropiación del espacio se ambientalizan cuando ciertos sujetos denuncian la ausencia de un acuerdo simbólico entre sus propias prácticas espaciales - presentadas como legítimas- y ciertas prácticas desarrolladas por terceros y vistas como indebidas. De esta forma, los conflictos socio-ambientales se distinguen de los conflictos por la tierra en la medida en que están en disputa los modos de uso y apropiación del espacio (territorio) y no solo la tenencia y propiedad?.

Al concebir este conflicto socio-ambiental como conflicto territorial, se sigue una línea de pensamiento de la geografía crítica conocida como el giro territorial, fuertemente influenciada por autores como Lefebvre, Foucault, Soja y Harvey, pero impulsada especialmente por movimientos sociales y por teóricos como Milton Santos y Porto-Gonçalves. Este giro se fundamenta en la interrelación de tres nociones claves: territorio, territorialización y territorialidad. Parte de la premisa de que el espacio es una construcción social que es apropiada (territorio) de diversas formas a través de la adecuación social de la naturaleza (prácticas espaciales) por diversos grupos humanos. En ese proceso de apropiación (territorialización) - en el cual están inmersas relaciones de poder, los sujetos se otorgan sentido a sí mismos y a su entorno, lo cual conduce a la configuración de identidades territoriales dinámicas y mutables, que materializan una configuración territorial específica (territorialidades $)^{10}$. Al complementar lo anterior con el pilar teórico consistente en que el espacio geográfico es una acumulación desigual de tiempos donde conviven simultáneamente diferentes temporalidades se entiende que en un mismo espacio pueden co-existir múltiples territorialidades o territorialidades superpuestas en disputa por la apropiación material y simbólica del espacio ${ }^{11}$. Es el caso a analizar, pues diversos actores con procesos de territorialización y territorialidades diferentes luchan por la apropiación y uso del Bloque San Juan.

Además, guiado por las ideas de Oslender y Escobar, también se utiliza esa sensibilidad geográfica para comprender la especificidad espacial del BSJ en cuanto esas particularidades ejercen un impacto definitivo en la evolución del conflicto. Para entender el desarrollo de éste, resulta fundamental comprender el lugar donde se

8 Siguiendo a Lefebvre y a Harvey se entiende por prácticas espaciales: "los flujos, transferencias e interacciones físicas y materiales que concurren en y a lo largo del espacio, y que garantizan la producción y reproducción social". Harvey, 1992, p. 201.

9 Esta definición de Acselrad fue esbozada durante el curso-seminario "Conflito Social e Meio Ambiente" (2016) del programa de posgrado del Instituto de Pesquisa y Planeación Urbana e Regional (IPPUR) de la Universidade Federal de Rio de Janeiro (UFRJ) y complementada con lo expuesto en: Acselrad, 2006.

10 Porto -Gonçalves, 2002, p. 230.

11 Santos, 1978; Haesbaert, 2007; Agnew \& Oslender, 2010. 
configura, pues cómo señala Escobar en el prologo del libro de Oslender: los conflictos y

los movimientos sociales no solo responden a las presiones del Estado y el capital, sino también a las especificidades -las intensidades bioculturales- del lugar del cual surgen y del cual se surten de ideas y sueños ${ }^{12}$.

De esta forma, a lo largo de la investigación, las realidades y particularidades territoriales del BSJ tales como su alta biodiversidad, las relaciones y tensiones interétnicas, los procesos de colonización, el conflicto armado y los procesos de desplazamiento forzado, entre otros, son un insumo fundamental para comprender el desarrollo del conflicto, aunque no se vea explícitamente reflejado en este corto texto.

\section{Estructura de oportunidades políticas y sociología pragmática.}

Además de este enfoque geográfico-territorial, se utiliza la sociología política. Es importante recordar que varios autores hacen uso de esos dos campos de conocimientos, pues muchos procesos de territorialización llegan a configurarse en conflictos políticos que se expresan en acciones colectivas. La particularidad de la aproximación propuesta son las relaciones que se plantean entre los diversos referenciales teóricos.

Dentro de la sociología política, el análisis se realiza sobre la base de un diálogo interno entre dos corrientes: estructura de oportunidades políticas (EOP) y sociología pragmática. Desde la óptica de la EOP el conflicto socio-ambiental podría entenderse como un conflicto político que se desarrolla dentro de ciertas oportunidades y restricciones políticas a través de determinados repertorios de acción que, entre otras, (re)configuran, (re)presentan y procuran la representación e instauración de frames (marcos interpretativos). Para entender esa argumentación es preciso definir y problematizar algunas de las nociones utilizadas. Por oportunidades políticas se entienden las dimensiones consistentes de la lucha política que incentivan a los sujetos a integrarse en el conflicto político, y las restricciones políticas como factores que los desincentivan ${ }^{13}$. A partir de las oportunidades y restricciones políticas los sujetos hacen uso de los repertorios de acción (conocidos o nuevos) para manifestarse e intentar alcanzar sus objetivos en el conflicto ${ }^{14}$. Estos repertorios no son propiedad exclusiva de los actores del movimiento u organización, sino que son una expresión de la interacción histórica y actual entre los movimientos sociales y sus opositores (por ejemplo, las grandes huelgas características de las luchas obreras, las manifestaciones de carácter pacifista del movimiento de independencia de la India, o la lucha armada de las guerrillas latinoamericanas, africanas y asiáticas). Por su parte, los frames se entienden como el conjunto de creencias movilizadas.. Más allá de lo que comúnmente se entiende como ideología, los frames son dispositivos desafiadores que resaltan y enfatizan la gravedad y la injusticia social, política, económica, ambiental y cultural de una condición social determinada, o redefinen como injusto y/o inmoral

12 Oslender, 2008A, p. 21.

13 Tarrow, 2009, p. 38.

14 McAdam, Tarrow \& Tilly 2009 
lo que antes era concebido como desastroso, pero tolerable o normal. Según Snow y Benford un frame es un

esquema interpretativo que simplifica y condensa el 'mundo allá afuera' subrayando y codificando selectivamente objetos, situaciones, eventos, experiencias y secuencias de acciones en un ambiente pasado o presente ${ }^{15}$.

Sin embargo, se hace una apropiación crítica de este enfoque teniendo en cuenta algunas de sus limitaciones y malinterpretaciones más comunes. Por un lado, generalmente los frames son entendidos desde una óptica utilitarista y psicologista, como simples recursos simbólicos para alcanzar objetivos, unificar organizaciones y vencer adversarios, ignorando las dimensiones políticas, sociales, culturales, históricas y geo-territoriales que están en juego. Por el otro, al centrar su enfoque en las oportunidades y restricciones políticas exógenas a la acción colectiva, fácilmente se dejan de lado muchos otros factores que influyen en el acto de movilización, como las experiencias individuales y colectivas de los actores envueltos, o los procesos de territorialización.

Para sortear el primer impasse, la noción de frame es complementada con la triada básica del giro territorial: territorio - territorialización - territorialidad. Esto sobre el supuesto de que, más allá de recursos simbólicos con objetivos concretos, los movimientos sociales, particularmente aquellos de carácter ambiental y territorial, por encima de todo expresan, defienden y procuran instaurar determinadas configuraciones territoriales (territorialidades) forjadas a partir de tipos particulares de relación y apropiación con el espacio (territorialización). De esta forma, en este texto se opta por utilizar el concepto de frame-territorial para referirse al "esquema interpretativo que simplifica y condensa el mundo" pero siempre ligado a los procesos históricos y espaciales concretos de territorialización, es decir atado a la triada territorio/ territorialización/ territorialidad.

Respecto a la segunda crítica, referida al desconocimiento de otros factores que influyen en el acto de movilización debido a la concentración excesiva en las oportunidades y restricciones políticas impuestas, es Cefaï, a través de la sociología pragmática quien ayuda a resolver el impasse mediante la noción de contextos de experiencia:

[m]ás que partir de estructuras económicas, sociales o políticas pre-construidas, o postular un tipo de racionalidad estratégica a priori, para entender lo que sucede en una movilización colectiva hay que investigar sobre los contextos de experiencia de los actores ${ }^{16}$.

Aunque el autor no define explícitamente qué son los contextos de experiencia, luego de una lectura detallada, se podría concluir que esta noción se refiere a todas aquellas circunstancias y experiencias que tienen un impacto significativo en la

15 Snow \& Benford 1992, p. 137. Apud Tarrow, 2009, p. 143.

16 Cefaï, 2011, p.138. 
movilización y en los sujetos que se movilizan, dando cabida a las oportunidades y restricciones políticas, pero también a otros aspectos que pueden ir desde trayectorias individuales y procesos de territorialización comunales, hasta el régimen socioeconómico global. Así, la noción de contextos de experiencia más que como un concepto cerrado y definido se debe entender como una herramienta metodológica y conceptual creada por cada investigador. Es el propio analista quien percibe y delimita cuáles factores de todo el universo de posibilidades son relevantes para entender las dinámicas de movilización y cuáles no. Siendo esta noción tan amplia y ambigua, requiere un uso juicioso y perspicaz de metodologías de investigación cualitativas como la entrevista a profundidad, la observación participante, la etnografía, la historia de vida, la micro-historia, etc., pues sólo a partir de este tipo de abordajes se pueden llegar a conocer parcialmente los contextos de experiencia de los actores: sus elecciones racionales, pero también sus elecciones "irracionales", sus conflictos y lealtades, sus apreciaciones estéticas, sus dudas éticas, y sus preferencias políticas, entre otras ${ }^{17}$. Particularmente en este conflicto los procesos de territorialización colectivos son unos de los contextos de experiencia que más influenciaron las dinámicas del conflicto y de la AASL. Pero además se analizan algunos contextos de experiencia individuales que resultan significativos dentro del conflicto y para el entendimiento de la problemática social; factores que comúnmente son ignorados por análisis estructuralistas donde los individuos no juegan un papel relevante. Claro está, este ejercicio se aleja radicalmente de ser un relato heroico que comprende las dinámicas sociales a partir de hechos individuales.

Una vez realizado este recorrido teórico podemos abordar la problemática del Bloque San Juan, entendiéndola como un conflicto político en donde los contextos de experiencia, las estructuras y oportunidades políticas, los frames-territoriales, los procesos de territorialización y los repertorios de acción colectiva, representan los elementos constitutivos del conflicto.

\section{Conflicto socio-ambiental en el Bloque San Juan}

Antes de entrar de lleno sobre el conflicto socio-ambiental resulta preciso hacer una breve referencia a algunas de las configuraciones biofísicas, históricas y geográficas principales del BSJ. Una parte estas configuraciones se ven posibilitadas e influenciadas debido a la ubicación particular entre el transito entre la cordillera de los Andes y la Amazonia al sur de Colombia (Piedemonte Andino Amazónico). Es el caso de los altos índices de biodiversidad (gran cantidad de aves, mamíferos, reptiles peces, flores y árboles, entre los que sobresalen el oso de anteojos, la danta, y el jaguar debido a que son grandes mamíferos endémicos que se encuentran en peligro de extinción, las complejas dinámicas ecosistémicos (se han identificado trece ecosistemas dentro del BSJ, destacándose los bosques naturales del orobioma Alto, Medio y Bajo de los Andes y la Orinoquia, entre otros), y la abundancia de recursos hídricos (nacimiento de alrededor de 27 ríos que desembocan en el Rio Putumayo, uno de los afluentes

17 Ibid. p.140. 
más grandes de la amazonia occidental, que a su vez desemboca en la mayor cuenca hidrográfica del mundo: el Rio Amazonas- Solimões) ${ }^{18}$. Además de esta biodiversidad biológica, el bloque también se caracteriza por su diversidad socio-cultural, pues aunque la mayoría de la población se auto-identifica como colonos-campesinos, en la zona coexisten once cabildos y cinco resguardos indígenas de las etnias Emberá, Inga, Pasto, Nasa y Awá19.

Respecto a las configuraciones históricas se deben resaltar tres dinámicas territoriales que se encuentran inter-relacionadas con la presencia diferenciada del Estado en la zona y que han afectado directamente la evolución del conflicto socio-ambiental: colonización forzada, conflicto armado y cultivos de uso ilícito. Contrario a las nociones de "territorios abandonados por el Estado" o "sin Estado" utilizadas en la literatura tradicional que conllevan la negación absoluta de la presencia de instituciones estatales de diversa índole, en este texto se opta por utilizar el concepto de presencia diferenciada del Estado. Esta noción hace referencia a un rasgo característico de la vida política colombiana:

la coexistencia de instituciones políticas de carácter formalmente democrático con redes de poder de hecho, de corte clientelista y territorios con escasa presencia estatal donde diferentes actores luchan por el control territorial ${ }^{20}$.

Desde mediados del Siglo XX colonos -campesinos e indígenas- de la región andina arribaron al BSJ, debido a la falta de oportunidades en sus lugares de origen, a la expansión en el altiplano de la violencia política y al excluyente modelo de explotación nariñense de hacienda-minifundio. Estos colonos procuraron reproducir las dinámicas de la economía campesina andina en este nuevo ecosistema, pero con el pasar de los años el crecimiento demográfico, la imposición de dinámicas ecosistémicas exógenas, y las restricciones territoriales de vinculación con los mercados regionales, llevaron al fracasó de esta economía campesina, y al consiguiente malestar general de la población. Debido a estas condiciones, a mediados de la década de los ochenta, el cultivo de coca pudo insertarse y legitimarse fácilmente en la zona gracias a la ausencia de instituciones estatales de control y a las facilidades de comercialización del cultivo, que permitieron la satisfacción de las necesidades materiales inmediatas de sus habitantes. Sin embargo, pese a los altos ingresos y el desarrollo de un incipiente comercio local, esta economía tendió a mantener la condición de marginalidad de la zona, situación que hoy en día continúa. Con relación al conflicto armado, más adelante se ahondará en la temática.

18 Duarte, 2016

19 Para explorar las relaciones, tensiones, estrategias y conflictos inter-étnicos e inter-culturales en el Bloque San Juan ver: Chaves, 2002; Azuero, 2017, Cap. IV “4.5: Relaciones y conflictos interétnicos en el BSJ."

20 González, Bolívar \& Vásquez, 2002. 


\section{ONG-ASCL en busca de recursos y derechos}

Los inicios del conflicto socio-ambiental y de la Asociación Ambiental el Salado de los Loros se remontan a 1992 con la conformación de la ONG "Asociación Campesina Salado de los Loros" (ONG-ACSL), a través del impulso de varios campesinos que, al percibir las intenciones de exploración petrolera en la zona por parte de la Empresa Colombiana de Petróleos (Ecopetrol) y tomando como ejemplo otros casos de organizaciones que consiguieron beneficios comunitarios, deciden organizarse para negociar las condiciones de inserción de la petrolera. A cambio de la exploración de petróleo pedían generación de empleos para la población local, obras de infraestructura comunitarias, proyectos socioeconómicos, y entrega de dinero a las Juntas de Acción Comunal (JAC).

En ese momento, la organización campesina se estructura alrededor de un determinado frame-territorial donde predomina la idea de que la injusticia y los atropellos en el territorio se generan debido a la presencia diferenciada del Estado en la región, al no reconocimiento de los derechos del campesinado, y a las características económicas de las empresas extractivas, pues no dejan excedentes ni dinámicas económicas estables en la zona.. Mayoritariamente se percibía al territorio como una fuente de recursos económicos, motivo por el cual no se hizo alusión al daño ambiental y social que la explotación del crudo generaría. En palabras del vicepresidente de la AASL:

organicémonos porque las compañías vienen, sacan, se llevan todo y no nos dejan nada. [...]Esa era como más o menos la visión que teníamos: Organizarnos pa' pedir²1.

Sobre esta perspectiva los miembros de la organización utilizan como repertorio de acción las reuniones consultivas y deliberativas como las asambleas comunitarias, las reuniones de las JAC y las reuniones de socialización del proyecto con representantes de Ecopetrol. Esa elección se relaciona con los contextos de experiencia colectivos, ya que en ese momento no conocían los impactos socioambientales de este tipo de actividades, ni habían sufrido experiencias de des-territorialización. Además no existía todavía una presión fuerte por parte de los grupos armados ilegales. Pero sobre todo, este repertorio resultó efectivo en la medida en que no había una oposición tajante entre los frames-territoriales enfrentados, pues discordaban en los medios, no en el fin: el crudo podía ser extraído, lo que debía discutirse eran las condiciones de explotación.

Como resultado de estas negociaciones Ecopetrol no tuvo dificultad en obtener en 1998 la licencia para tres prospectos de perforación en la zona y pudo realizar una perforación exploratoria. Sin embargo, en 1999 abandonó el pozo debido a que

los resultados de las pruebas de producción no fueron positivos [... y ] a la imposibilidad de ingresar a la zona [...] debido a los problemas de orden público de la región. ${ }^{22}$

En ese periodo la ONG-ACSL consiguió sus objetivos: logró aglomerar los intereses

21 Grupo Focal 1: Directivos de la AASL. Enero de 2016.

22 Agencia Nacional de Licencias Ambientales (ANLA). Resolución 0762 del 13 de septiembre 2002. 
de las comunidades campesinas de la zona y negoció con Ecopetrol las condiciones de inserción. Al darse cuenta de la efectividad, el impacto y la amplia recepción de su labor, deciden continuar con la organización, reorientando sus objetivos hacia la reivindicación de los derechos sociales, económicos y políticos de la comunidad ante el Estado:

La compañía se fue pero seguimos organizados, y dijimos, bueno organicémonos pero para reclamar nuestros derechos ante el gobierno, reclamando vías, proyectos productivos $^{23}$.

De esta forma durante el periodo en el que no hubo perspectivas de explotación petrolera, y por lo tanto el Estado perdió en gran parte su interés en el BSJ, se utilizaron las grandes movilizaciones como repertorios de acción para llamar la atención del gobierno respecto a sus condiciones socioeconómicas y para exigir sus derechos ante un Estado diferencial. Este proceso se encuentra relacionado con las dinámicas de movilización regional, pues por esos años sucedieron las famosas marchas cocaleras de 1994 y 1996 que, cómo Ramírez demostró, más allá de manifestarse contra la erradicación de los cultivos de uso ilícito, buscaban el reconocimiento y la reivindicación política de los derechos sociales, políticos y económicos del campesinado putumayense ${ }^{24}$.

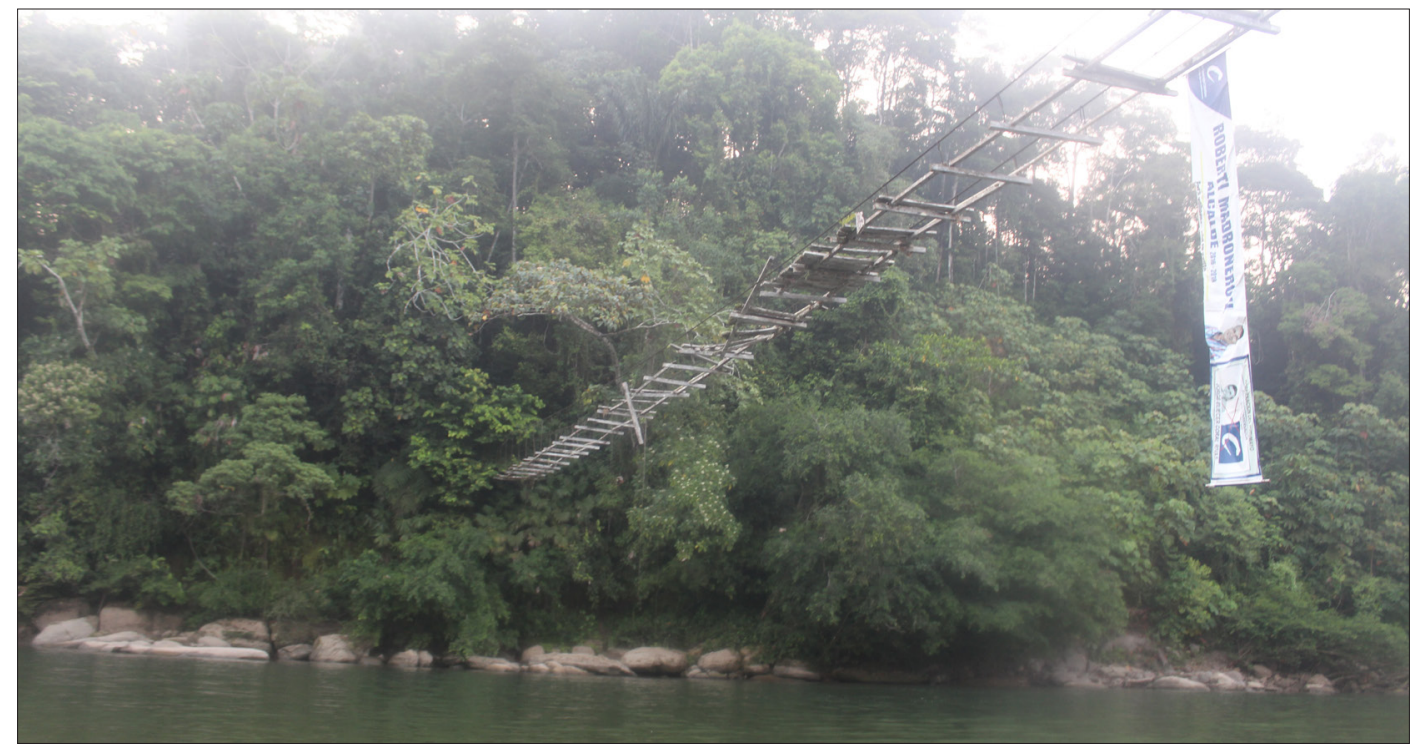

Figura 2. Pescando Votos. Imagen que da cuenta de la presencia diferenciada del Estado en el BSJ. Por un lado, no se realizan inversiones en infraestructura, por el otro la maquinaria política hace presencia con publicidad política para las elecciones incluso en la infraestructura abandonada.

Fuente: Azuero, 2016

Ahora bien, para analizar la evolución del conflicto socio-ambiental resulta preciso referirnos a cómo el conflicto armado golpeó la región ${ }^{25}$. Esto debido a que

23 Grupo Focal 1. Op. Cit.

24 Ramírez, 2001.

25 En este artículo sólo se hará referencia a aspectos concretos del conflicto armado que (re)confi- 
algunas de estas dinámicas pueden entenderse como restricciones dentro de las estructuras de oportunidades políticas y como catalizadores de mudanzas radicales en los procesos de territorialización y en los contextos de experiencia, que a su vez (re)configuraron las formas de organización y de acción colectiva en el BSJ.

A mediados de la década de 1980 el Frente 32 de las FARC-EP llegó al BSJ y a través de las armas, el miedo y la administración de la justicia ejerció un importante dominio territorial en la zona. Durante este lapso existió un diálogo entre la ONGACSL y la guerrilla, y esta última procuró cooptar a la organización dentro de su estructura político-militar a través de la coacción armada, pero la comunidad se negó:

Ellos [FARC-EP] querían que como organización hiciéramos parte de ellos -nosotros les dijimos- no, vea, esto es una organización netamente campesina con ideas campesinas. De todas maneras les agradecemos pero no queremos hacer parte de la política armada ${ }^{26}$.

Lo anterior puede considerarse como una presión, pero no una restricción política total a la organización y a la movilización social, pues si bien se forzaba el diálogo con el grupo armado, y se limitaban ciertas formas de organización, no se restringía completamente su accionar.

Esta dinámica duró hasta 1998 cuando en el departamento surgió el grupo paramilitar Bloque Sur Putumayo de las Autodefensas Unidas de Colombia (BSP-AUC), escalonando el conflicto armado y los hechos victimizantes sufridos por la población civil, especialmente el desplazamiento forzado. Como se ve en la Figura 3, desde la incursión del BSP-AUC los episodios de desplazamiento forzado se incrementaron progresiva y significativamente en el municipio de Villagarzón hasta el año 2008 (año de desmovilización del BSP-AUC).

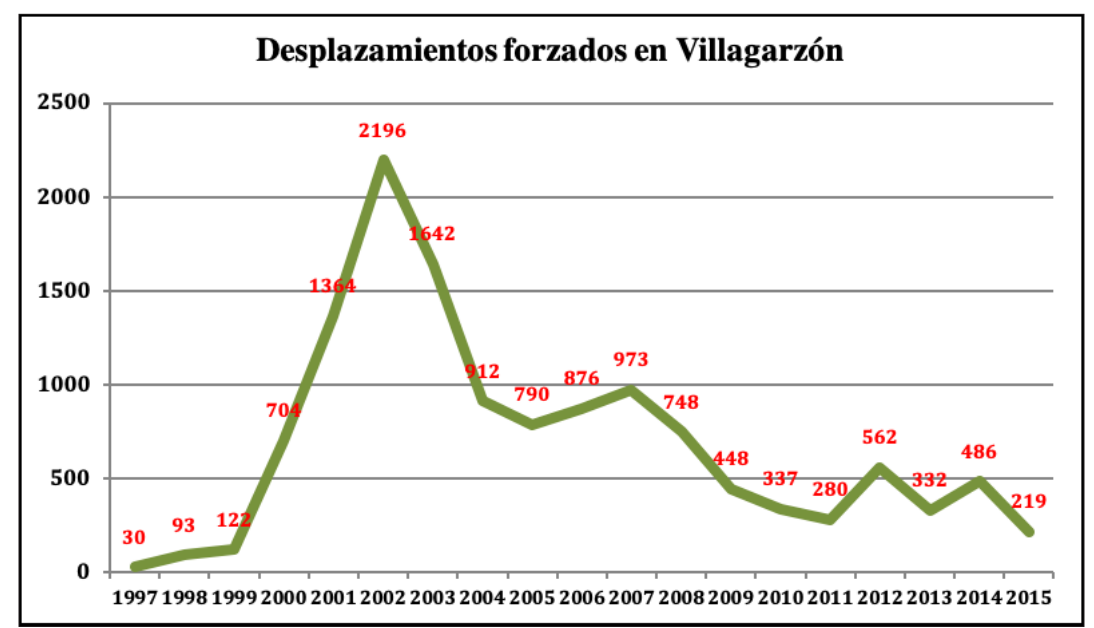

Figura 3. Gráfico de desplazamiento forzado en Villagarzón (1997-2015). Fuente: Elaboración propia con datos del RUV, 2016.

guraron la evolución del conflicto socio-ambiental. Para un análisis profundo del conflicto a escala regional y departamental ver: CNMH, 2012 y 2015; Vásquez, Vargas, \& Restrepo, 2011. A escala local ver: Azuero, 2017. Cap. 4.

26 Entrevista 1. Miembro de AASL. Enero de 2016. 
Frente al desplazamiento forzado, es importante abrir un paréntesis para anotar las particularidades de cómo se desarrolló en el departamento y en el BSJ. En Putumayo este fenómeno se dio en su gran mayoría a través del abandono forzado (83\% de las solicitudes ante la Unidad de Restitución de Tierras -URT) y solo un pequeño porcentaje a través de despojo (13\% de la solicitudes) ${ }^{27}$. El Centro Nacional de Memoria Histórica (CNMH) concluye que este predominio de casos de abandono, a diferencia de otras regiones con altos índices de despojo como el Caribe, responde a "los papeles que han desempeñado la economía de la coca y las dinámicas del conflicto armado en la construcción territorial de este departamento", pues, entre otras, el narcotráfico no necesita de la propiedad sobre la tierra para obtener sus rentas $^{28}$. Esta dinámica se reprodujo en el BSJ lo cual permitió que muchos de sus pobladores pudieran retornar y emprender procesos de (re)territorialización, como se verá después.

Durante el periodo de escalonamiento del conflicto armado de 1998 (conformación del BSP-AUC y puesta en marcha del Plan Colombia) a 2006 (expulsión del F32 -FARC de la zona y desmovilización del BSP-AUC) los habitantes del BSJ sufrieron algunas de las dinámicas territoriales esbozadas por la geografía del terror, planteada por Oslender ${ }^{29}$. Se configuraron paisajes del terror que quedaron impresos en los imaginarios y de manera material en múltiples espacios transformados y/o vaciados como por ejemplo las casas abandonas. El terror instaurado por los actores armados llevó a una transformación dramática del sentido del lugar en la medida en que las experiencias y memorias de los hechos víctimizantes, junto con los miedos y las angustias fueron (re)configurando los territorios de sociabilidad en sentidos de lugar aterrorizados, donde no tenían cabida la amistad, la confianza y la solidaridad, afectando los esfuerzos organizativos de la ONG-ACSL. Ese proceso fue de la mano con las restricciones en la movilidad de los pobladores, especialmente en lo que se refiere al tránsito entre las áreas rurales y urbanas, pues los pobladores del BSJ no podían desplazarse al casco urbano de Villagarzón so pena de ser catalogados como guerrilleros. Finalmente, el desplazamiento forzado al que se vieron obligados muchos de los habitantes del BSJ debido a las amenazas y asesinatos ocurridos en la zona, terminó por establecer un proceso de des-territorialización, llevando a la pérdida del control territorial físico y simbólico de la población local durante varios años.

Además de estos factores, en este contexto de agudización del conflicto armado, la ONG-ACSL se ve forzada a desintegrarse debido a las amenazas, asesinatos, el desplazamiento forzado de sus miembros y la presión directa de los actores armados.

27 El abandono forzado ocurre cuando la víctima se ve obligada a dejar sus tierras para proteger su vida, integridad y libertad y la de su familia, razón por la cual se ve impedida a hacer uso de su predio. El despojo se configura cuando terceros (sean o no grupos armados) usan y/o sacan provecho de las condiciones de violencia para apropiarse del predio. El despojo se puede configurar luego del abandono forzado.

28 CNMH, 2015, p. 107.

29 Oslender, 2008b. 
Por un lado, los paramilitares los señalaban como auxiliadores de la guerrilla por ser población rural y defender reivindicaciones locales de índole social, por lo tanto los consideraban objetivo militar. Por el otro, y en mayor medida, el F-32 FARC-EP presionó a su disolución debido a: 1) el escalonamiento del conflicto y de combates; 2) la negativa de vincularse orgánicamente con la subversión; 3) la amenaza de autoridad político-territorial que representaba, y 4) los vínculos que estableció con algunas instituciones estatales, pues sus objetivos se enfocaban en la demanda de los derechos económicos y sociales ante el Estado ${ }^{30}$. En esta etapa se impuso entonces una restricción política total a la organización por parte de los grupos armados ilegales:

[la ONG] se desarticula por presión de los grupos armados. Por desplazamiento forzado, por presión de ambos bandos: los grupos irregulares, tanto los de extrema derecha como los de extrema izquierda. ${ }^{31}$

Al analizar lo sucedido, puede concluirse que en ese momento hubo una disputa de territorialidades superpuestas, no entre la comunidad y la empresa petrolera, quienes compartían una misma visión del territorio: la explotación de petróleo, sino entre la comunidad y los actores armados, especialmente las FARC-EP. Estos últimos concebían el territorio como un refugio militar y económico, en la medida en que podían resguardarse de la ofensiva militar y paramilitar originada en las zonas urbanas, y además obtenían importantes rentas de los cultivos ilícitos. En esa disputa de múltiples territorialidades primaron durante mucho tiempo los actores armados al margen de la ley debido al uso de repertorios de acción basados en la violencia.

\section{AASL ¡No al petróleo!}

Generalmente en Colombia, luego de procesos traumáticos de desplazamiento forzado por el conflicto armado, el retorno de la población y la puesta en marcha de procesos de re-territorialización resultan muy problemáticos, debido a factores como la persistencia de las condiciones que forzaron el desplazamiento, la continua presencia de actores involucrados directa e indirectamente con el desplazamiento, las artimañas jurídicas que configuran el despojo e impiden el uso legal de los predios, las marcas traumáticas en el paisaje que impiden la posibilidad de nuevos sentidos de lugar y de re-apropiaciones simbólicas y la imposibilidad de (re)construir antiguos y nuevos lazos de sociabilidad debido a los traumas generados. En algunos de los casos en que el retorno es posible suceden procesos de re-territorialización por parte de la población local que conllevan a "una re-definición de las relaciones sociales anteriores y una reconstrucción de los paisajes de miedo en espacios de solidaridad y de paz" ${ }^{32}$. Fue

30 Ramírez ha evidenciado como en el Putumayo la persecución de los líderes y organizaciones sociales por parte de las FARC-EP respondía principalmente a que la guerrilla no permitía la autonomía de organizaciones que van tomando fuerza debido a que compiten y representan una amenaza a su autoridad política. 2001, p. 321.

31 Entrevista 2. Miembro de la AASLBS. Enero de 2016.

32

Oslender, 2008b, p. 4 
esto lo que sucedió en el Bloque San Juan.

Luego del repliegue del F-32 de las FARC-EP debido a la ofensiva paramilitar y a la puesta en marcha del Plan Colombia, y de la posterior desmovilización del BSP-AUC en 2006, el BSJ quedó bajo el dominio de la fuerza pública, generando el des-escalonamiento del conflicto armado. Como consecuencia, a partir del año 2006 muchas de las familias desplazadas inician el retorno a sus predios y procuran recomponer sus vidas comunitarias. A diferencia de otras regiones, este retorno pudo realizarse en condiciones comparativamente favorables en la medida en que, como ya se señaló, en esta región el desplazamiento forzado sucedió mayoritariamente bajo la modalidad de abandono forzado y no de despojo, lo cual llevó a que las familias no encontraran problemas jurídicos significativos para establecerse de nuevo, y a que pudieran superar las trabas físicas, simbólicas y emocionales.

Fue durante este proceso cuando, tomando como base el trabajo organizativo de la ONG-ACSL y otros procesos de ámbito veredal, surge la Asociación Ambiental El Salado de Los Loros (AASL), que reunió a las Juntas de Acción Comunal de quince veredas que reconocían la cuenca alta del Río San Juan y El Salado de los Loros como territorios fundamentales para su identidad colectiva. En este nuevo proceso también se incluyen progresivamente algunos resguardos y cabildos indígenas de las etnias nasa, inga, awá y algunos emberás sin jurisdicción territorial que comparten la misma visión territorial-ambiental del BSJ, motivo por el cual su nombre pasa de "Asociación Campesina" a "Asociación Ambiental".

A partir de entonces, y debido a las restricciones y oportunidades políticas, a las particularidades de los contextos de experiencia colectivos e individuales, y al proceso de re-territorialización comunitario, la asociación inicia un proceso de transformación gradual. Poco a poco los frames-territoriales empiezan a cambiar a una posición radical frente a la explotación petrolera y a la defensa del medio ambiente, y esa mudanza es acompañada por cambios en las formas de organización y en sus estrategias y repertorios de acción colectiva.

Con relación a las se destaca una mudanza fundamental; la zona ya no es disputada violentamente por actores armados ni tampoco se encuentra sobre el dominio único de la guerrilla. Ahora la disputa no es entre las territorialidades superpuestas de los actores armados y la población local, sino entre esta última y la empresa Gran Tierra Energy Inc, como se verá adelante.

En este proceso de re-territorialización y de re-estructuración de la organización juegan un rol fundamental los contextos de experiencia colectivos de los habitantes del BSJ, pero además algunos de ciertos líderes. Respecto a los contextos de experiencia colectivos, el desplazamiento forzado de gran parte de la población y las experiencias y lecciones aprendidas van a influir significativamente en la percepción comunitaria del territorio, y de esta forma en su frame-territorial. Como lo expresaron muchos de los habitantes con quienes se compartió, después de sufrir el desplazamiento y de retornar, sienten que se forjó una "mayor conexión" con su territorio. A partir del sentimiento colectivo de pérdida de territorio se fue (re)configurando una identidad territorial cuyo 
pilar fundamental es evitar un nuevo proceso de des-territorialización, lo que a su vez favoreció un posicionamiento crítico frente a las perspectivas de explotación petrolera:

Nos dispersamos como asociación, y hermano, uno estando lejos de la tierrita, [...] uno créame que se da cuenta de que tiene una conexión con esa zona. Ese tiempo fuera fue muy duro[...]. Entonces ya cuando uno vuelve al territorio [...] ya créame que uno no va a estar dispuesto a salir otra vez. Uno como ya sabe qué es estar afuera, créame que uno va a defender este territorio a capa y espada contra lo que sea, que si se vienen las petroleras, que las mineras, que los paracos [paramilitares], que los guerros [guerrilleros], que el ejército, que cualquiera que venga aquí a sacarnos o a afectar nuestra agua, nuestro monte, los animalitos, mejor dicho a perjudicar nuestro territorio, no la va a tener fácil. Por lo menos yo de aquí no me voy, y sé que así es el pensar de muchos compañeros. ${ }^{33}$

Paralelo a este proceso colectivo de re-territorialización y de re-configuración de identidades territoriales, las experiencias particulares de Erasmo, Chico y Berto como líderes de la comunidad van a desempeñar una papel substancial en esa nueva reconfiguración de identidades territoriales, especialmente en lo que respecta a la percepción, relación y cuidado del medio ambiente y del territorio ${ }^{34}$. Por un lado, Chico, líder e intelectual de la zona, a través de un movimiento ambiental, filosófico y espiritual, problematiza la relación naturaleza humana y naturaleza no-humana, las causas e impactos del cambio climático y del calentamiento global, y los fundamentos de una ecología que incluya las actividades humanas, y llega a la conclusión de que el BSJ, debido a las características geográficas, ambientales, sociales y culturales debe preservarse sosteniblemente a través de una "ecología humana" ${ }^{35}$. Junto con otros compañeros, realiza labores pedagógicas sobre el cuidado y defensa del territorio, y de las relaciones entre los humanos y su entorno; "concientizando" a la población para acabar con la cacería de animales silvestres, la pesca indiscriminada, realizar prácticas de cultivo agroforestales, y sobre el cuidado de las nacientes de agua, los caños y los ríos. Por su parte, Berto, quien desde la infancia es reconocido en la zona por "conocerse de arriba abajo todo el monte, sus animales, plantas y espíritus" ${ }^{36}$, establece una fuerte relación con esta iniciativa de ecología humana y con las labores pedagógicas. Además realiza un monitoreo de la zona dejando evidencia (fotografías y videos) de la gran biodiversidad faunística y florística del territorio.

Erasmo, quien durante años ha trabajado como mano de obra en diferentes campamentos petroleros, inició también una labor pedagógica con la comunidad. Desde su experiencia como trabajador les explicó los impactos ambientales, sociales, económicos y culturales negativos de esta actividad sobre el territorio. . Este ejercicio

33 Entrevista 4. miembro AASLBS. Enero de 2016.

34 Nombres ficticios.

35 Debido a la persecución y estigmatización que ha sufrido este culto, sobre todo por parte de sectores tradicionales de la Iglesia Católica y Cristiana, y por pedido del mismo Chico, el nombre de ese movimiento no se hará público.

36 Entrevista 5. Campesino del Bloque San Juan. Septiembre de 2016. 
genera un fuerte impacto en la población:

Él trabaja con las petroleras. Ese día que escuché a [Erasmo], el nos dio una explicación de qué era la sísmica, qué era la explotación de petróleo y toda esa joda -como él trabaja es en eso- que qué daños causaba, que ya no íbamos a poder tomar agua, que la tierra ya no sería igual, que los carro-tanques dejan todo vuelto mierda, y que la verdad es muy poca la gente de acá de las veredas que les dan camello [trabajo]. Así fue que uno se fue dando cuenta de que no era tan bueno que la compañía entrara ${ }^{37}$.

Estas tres experiencias individuales, junto con las experiencias colectivas del desplazamiento, influyeron en el proceso de re-territorialización de sus pobladores y fueron aglomerándose en torno a un sector de la población y de la AASL, configurando un frame-territorial basado en la búsqueda de una relación armónica con el ambiente, y en el rechazo a la explotación de petróleo. Es lo que ellos llaman "la nueva y buena conciencia ecológica"s8.

Durante ese proceso de reconfiguración de la AASL, se enteran en el 2012 de la existencia de contratos de exploración y producción petrolera de dos bloques (PPN y Put10) dentro del BSJ. En estos se asignan los bloques abandonados por Ecopetrol a la empresa de origen canadiense "Gran Tierra Energy Inc." (GTE) (Figura 4).

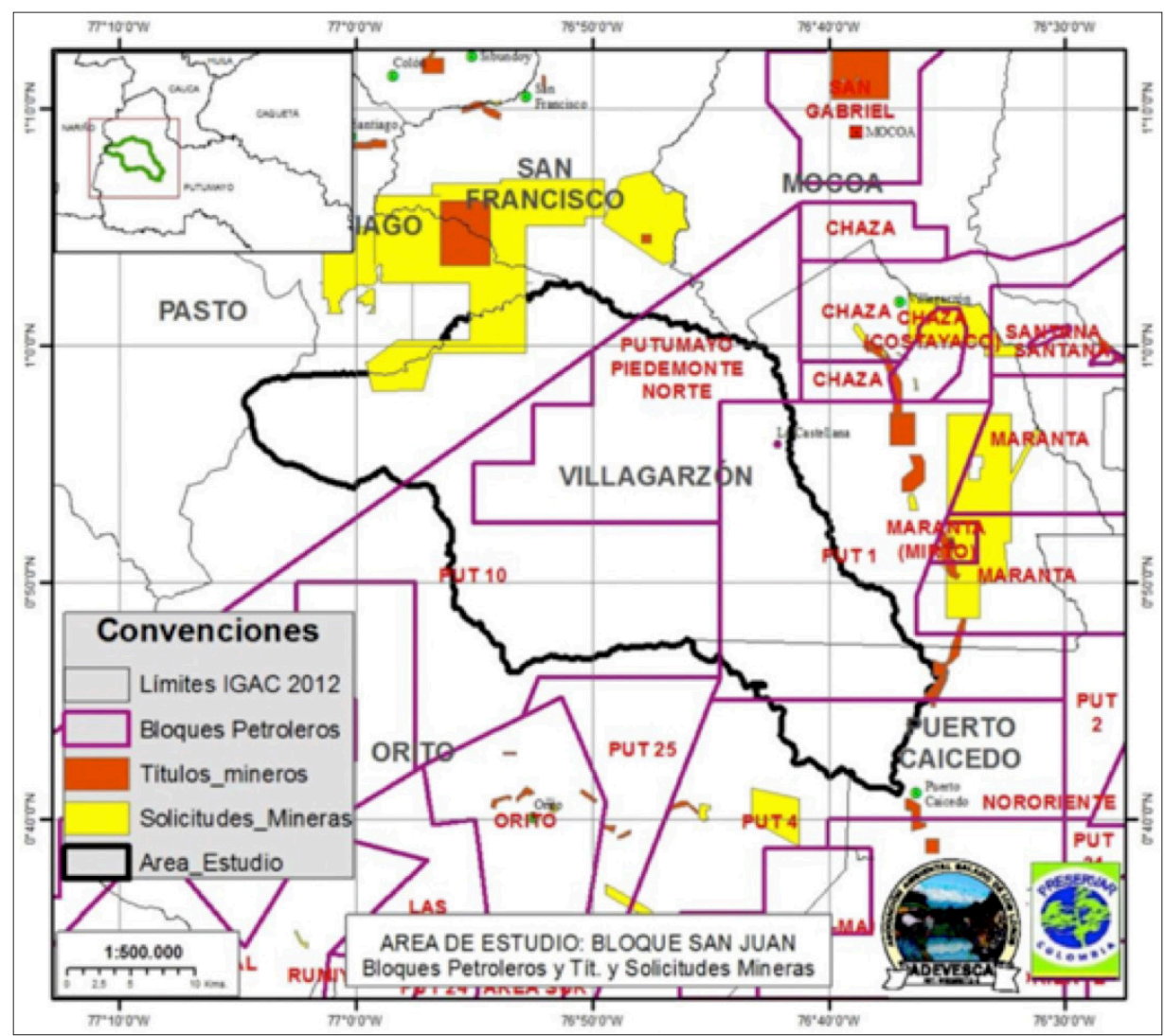

Figura 4. Mapa de Bloques y títulos petroleros y mineros en el Bloque San Juan. Fuente: Duarte, 2016

37 Entrevista 6. Campesino del Bloque San Juan. Enero de 2016.

38 Por falta de espacio no se puede ahondar en el análisis de la configuración de este frame-territorial. Ver Azuero 2017, cap. 6. 
Para hacer frente a esta intención de exploración por parte de GTE, un porcentaje mayoritario de la comunidad decide organizarse en torno a la AASL. En ese momento la comunidad y la organización se encontraban divididas entre quienes pensaban que la asociación debía seguir su antiguo rumbo y negociar la entrada de las petroleras, y por otro lado, quienes defendían esa "nueva y buena consciencia ambiental", y se oponían sobre cualquier circunstancia a la entrada de éstas. El grupo que rechaza la exploración petrolera reforzó sus ejercicios pedagógicos, como lo venía haciendo desde antes.

Por su parte el grupo que defendía la explotación de petróleo empieza a negociar con la petrolera. A cambio del permiso para realizar pruebas sísmicas exigen grandes sumas de dinero para la realización de proyectos socioeconómicos y de infraestructura comunitarios. Luego de varias reuniones apenas consiguen negociar la entrega de cinco mil dólares para tres de las veredas, cifra irrisoriamente baja comparada con sus expectativas iniciales. El hecho de haber obtenido tan poco dinero, junto con el intenso trabajo pedagógico de conciencia ambiental y territorial y los procesos de (des) y (re) territorialización va ocasionando que la comunidad y los miembros de la asociación cada vez más se posicionen en contra de la entrada de la petrolera, y vayan adoptando el frame-territorial de la nueva y buena consciencia ambiental.

Esta transformación se va a cristalizar en Octubre de 2012, cuando en reunión con la Agencia Nacional de Hidrocarburos (ANH) y la Corporación para el Desarrollo Sostenible del Sur de la Amazonia (Corpoamazonia), la comunidad manifiesta que no van a permitir la exploración de hidrocarburos en la zona. Ante esta situación GTE exige que respalden el carácter democrático de esa posición a través de una recolección de firmas en las veredas involucradas. Luego de un tiempo, en el Comité Regional de la Industria Petrolera (CRIPET) entregan la lista con las firmas que expresaban el carácter democrático de la decisión y la empresa se compromete a respetarla. Sin embargo, posteriormente los representantes de GTE retaron a la comunidad a que demostrara la importancia ecológica e hídrica que decían estar protegiendo. Como respuesta, en julio del 2013, el director departamental de GTE recorrió durante tres días el BSJ en compañía de dos líderes de la zona. En esa travesía el ejecutivo de nuevo intentó persuadir a los líderes para que "dejaran entrar" a la empresa a cambio de jugosos beneficios individuales ${ }^{39}$. Ellos se negaron.

En el mismo CRIPET Corpoamazonia se comprometió con la comunidad a no dar el concepto favorable para la exploración de crudo, pues reconoció los riesgos de la actividad sobre la zona. Pero, para cumplir este compromiso, se le exigió a la asociación la entrega de un "documento técnico" que sustentara tal decisión. En febrero de 2014, en otra reunión entre ANH, Coporamazonia y la comunidad, los miembros de la asociación expusieron una pieza audiovisual con 180 fotografías y varios videos que habían recogido meses atrás con ayuda del Fondo Mundial para la Naturaleza (WWF) que demostraban las condiciones exigidas para la de preservación de la zona. Además, en esa reunión hicieron uso de otro repertorio de acción: el debate jurídico.

39 CNMH, 2015, p. 169 
Demostraron que su oposición a la exploración de crudo se encontraba amparada en el Esquema de Ordenamiento Territorial Municipal, pues según el artículo 103 las áreas del municipio de Villagrazón ubicadas entre los 1.000 y los 3.400 msnm se deben reconocer como "Tierras Forestales para la Protección" debido a que son zonas de "nacimientos y vertientes hídricas" y por lo tanto son territorios:

apt[os] para la protección, conservación e investigación con fines científicos, moderadamente ap[tos] para actividades de ecoturismo, uso múltiple del bosque, [...] y no apt[os] para la implementación de actividades agroforestales, ganadería, piscicultura, agricultura y minería.

Al terminar esta reunión la ANH y Corpoamazonia se comprometieron a no otorgar las licencias ambientales para la exploración mientras no se estudiara con mayor profundidad la situación. En ese momento, supeditados por los contextos de experiencia y las oportunidades y restricciones políticas, los repertorios de acción seleccionados por parte de los dos actores enfrentados fueron semejantes. La AASL hizo uso de los siguientes: 1) labores pedagógicas; 2) apropiación de espacios de negociación para reafirmar su posición; 3) uso de material audiovisual y fotográfico con respaldo de organizaciones internacionales; e 4) interpretación jurídica del ordenamiento territorial municipal. Por su parte, GTE usó los siguientes repertorios: 1) labores de persuasión a través de promesas de incentivos individuales; 2) apropiación de los espacios de negociación para reafirmar su posición; 3) desconocimiento de hechos significativos en el proceso (firmas recolectadas, visita guiada, "documento técnico"; y 4) argumentación jurídica.

\section{Paro Acción directa}

Frente a esta situación GTE incrementa el uso de ciertas acciones que generalmente resultan efectivas dentro de los repertorio de acción tradicionales de las empresas extractivistas: 1) división y diferenciación de los habitantes, y 2) ofrecimiento de incentivos individuales y colectivos. Según habitantes del BSJ la compañía contacta por separado a algunos líderes de los cabildos awá e inga ubicados en el alto San Juan, entre los límites de Villagarzón y Orito, ofreciéndoles beneficios económicos y laborales concretos a cambio del permiso para el ingreso de la compañía en la zona, a lo cual acceden sin que la mayoría de los habitantes se enteren.

Mientras tanto la AASL, previendo arremetidas de ese tipo, emplea la figura centinelas comunitarios, estrategia que consiste en que individuos de diferentes zonas del BSJ informan regularmente a las directivas sobre actividades sospechosas. En la zona del alto San Juan se contaba con tres centinelas que hacía bastante tiempo no se comunicaban con la asociación. Desconfiados, tres miembros de la asociación deciden ir hasta ese punto para ver qué sucede. Al llegar se dan cuenta que GTE había negociado por separado con algunos líderes del resguardo inga, incluidos los centinelas, ofreciéndoles trabajo y beneficios económicos a cambio del permiso para realizar la exploración sísmica, que para entonces ya tenía seis líneas exploratorias. 
Ante esta situación, en un primer momento dialogan con los trabajadores y les exigen el cese de actividades ya que no tenían la autorización legal, ni de la comunidad, a lo cual los trabajadores responden negativamente.

Ante este escenario, deciden convocar asambleas extraordinarias en las veredas y en los cabildos indígenas nasa y awá del BSJ para discutir qué acciones tomar. En estas se decidió que se haría un paro: repertorio de acción presente en el imaginario colectivo que había resultado efectivo en diversos momentos, como por ejemplo en las grandes marchas cocaleras de finales del siglo XX y frente a la erradicación de cultivos ilícitos. Como afirma Tarrow, los actores tienen una historia y una memoria de la acción colectiva, de la cual los repertorios hacen parte fundamental, y éstos al haber sido efectivos en el pasado muchas veces se repiten ${ }^{40}$. Este vínculo es señalado por uno de los campesinos que participó activamente:

La idea nació yo creo que por lo que ya habíamos hecho con los de la erradicación y con los paros del noventa y pico. Así como paramos a los erradicadores y exigimos nuestro derechos, podemos parar a los petroleros ${ }^{41}$.

En un primer momento el paro consistió en el arribo de varios habitantes para impedir el trabajo en líneas de exploración y restringir las vías de acceso. Esto desembocó en un conflicto, no solo con la empresa que se vio obligada a parar sus actividades, sino también con algunos miembros de los cabildos inga y awá, que inclusive se manifestó en enfrentamientos que dejaron heridos de machete y en amenazas directas con armas de fuego. Se observa cómo la acción de la empresa a través de la división de los actores involucrados sobre la base de concesiones particulares, no solo resulta efectiva para la puesta en marcha de las actividades de sísmica, sino que llevó a la configuración de un nuevo conflicto social, que a su vez resulta favorable para sus intereses. En palabras de un habitante:

"Las petroleras manejando su táctica y experiencia utilizan a la misma comunidad para fraccionarla, dividirla y sacar provecho [...] Ella [la corporación] encuentra y coopta a un grupo para que defienda los intereses de la empresa petrolera, y los reales ambientalistas que defendemos el patrimonio natural, territorial y cultural, pues nos enfrentamos a eso [...]. Se convierte en un conflicto socio-ambiental, o sea ambiental pero también social entre nosotros mismos, por motivación y apoyo de la industria petrolera" 42 .

Haciendo referencia al tema de violencia, se debe anotar que durante el paro ningún actor armado intervino ni tomó partido directamente. Por el lado de la guerrilla, ésta se abstuvo de apoyar o reprimir la movilización: “-dijeron- ustedes son los de ese territorio hagan ustedes mismos lo que crean que tienen que hacer, nosotros no nos

40 Tarrow, 2009.

41 Entrevista 8. Campesino que participó en el paro. Enero de 2016.

42 Entrevista 9. Miembro de la AASLBS. Septiembre de 2016. 
vamos a meter, si no se mete el ejército o los paracos"43. Por su parte, el ejército fue enviado por el alcalde de Orito para reprimir la movilización, pero al percibir que se trataba de un conflicto entre comunidades y no entre actores armados, decidió no intervenir. Respecto a la presencia y presión de paramilitares, a pesar de que fueron pocas las menciones directas a esos grupos durante el paro, en algunas conversaciones y entrevistas se pudo percibir, a través de referencias indirectas, silencios y gestos, que hubo una presión por parte de actores desconocidos y existió un fuerte temor de una nueva arremetida paramilitar en contra de los participantes del paro, situación que no se manifestó sino hasta el final, con la quema de una maloca del cabildo nasa.

Paralelamente al paro se realizaron reuniones deliberativas entre los representantes de las comunidades, GTE, ANH, Corpoamazonia y los alcaldes de Orito, Villagarzón y Puerto Caicedo, en las cuales no se llegó a ningún acuerdo.

Luego de dos meses de paro (fuera del hogar, delegando responsabilidades como cuidado de cultivos, animales y familia, etc.) y ante la negativa de GTE de abandonar la zona, en un momento de efervescencia la comunidad decide que la única forma viable para detener las actividades exploratorias es a través de acciones directas violentas: queman cinco taladros y algunas herramientas de dotación y detonan varios de los explosivos utilizados para la exploración. Este momento de agitación, y de rechazo a las actividades exploratorias es retratado por un campesino que participó en los hechos.

Nosotros queríamos conversar con los que los mandaban a ellos pero nunca fueron, solamente mandaban al social, y el social no tiene el poder pa' decidir. [...]Nosotros ya queríamos era hablar directamente, ya pa' decirles que nosotros no íbamos a permitir la entrada de ellos de ninguna manera, ni negociando, ni hablando, ni nada. [...] La gente dijo: no, a esos es hay que echarles es candela y ahí si les enseñamos nosotros a ellos. Entonces ya ellos [trabajadores] decían -si eso es así pues nosotros nos vamos-, y la gente de la comunidad empezó a hacer eso. A echarle candela a los plásticos, a las herramientas, a las cositas que ellos tenían de trabajar. [...]Ya cuando hicimos eso fue que ellos sí se fueron ${ }^{44}$.

Como se observa en la cita, la acción directa-violenta es catalizada por dos sentimientos compartidos entre los manifestantes y relacionados directamente con los contextos de experiencia colectivos. Estos son, frustración frente al diálogo con los representantes de la empresa y así mismo con las acciones jurídicas, legales y pacíficas para defender el territorio, y el fuerte arraigo territorial el cual, como ya vimos, se fortalece debido a los procesos anteriores de desplazamiento forzado y de posterior re-territorialización: "Así nos cueste la vida" fue una de las consignas que más se oyó durante el trabajo de campo.

Aduciendo problemas de orden público GTE decide abandonar los campamentos y frenar las actividades exploratorias. Ya luego, ante la salida de la empresa y la presión continua de la comunidad, Corpoamazonia resuelve suspender temporalmente

43 Entrevista 10. Campesino que participó en el paro. Enero 2016.

44 Entrevista 11 - campesino que participo en el paro. Septiembre 2016. 
las concesiones ambientales y de vertimientos mediante la resolución 0025 del 26 de enero de 2015.

Sesenta días después de que GTE se hubiera retirado, quince encapuchados armados ingresaron al cabildo nasa de Bellavista (que había servido como campamento base durante el paro) lanzaron granadas e incendiaron la maloca de la comunidad. Hasta el momento las investigaciones no han dado con los responsables.

Por el momento GTE no ha vuelto a ingresar a la zona, pero ha seguido con la estrategia de contactar independientemente a líderes para convencerlos de la conveniencia de la explotación petrolera. Mientras tanto, la comunidad campesina e indígena agrupada en la AASL ha empezado a construir una propuesta de ordenamiento territorial alternativo que busca blindar legalmente el territorio. Además, frente a las amenazas de violencia latentes, está en proceso de creación la Guardia Indígena Campesina del Bloque San Juan, cuyo propósito es “defender hasta la muerte el territorio de las continuas amenazas de destrucción territorial"45.

\section{Reflexión para el pos-acuerdo de paz}

En esta sección se presenta una pequeña reflexión sobre el análisis del conflicto socio-ambiental del BSJ con relación a la firma e implementación del acuerdo de paz entre el Gobierno y las FARC-EP (noviembre de 2016). De las varias e interesantes reflexiones que se pueden suscitar, solo se dedicarán pocas líneas relacionadas con la situación de la explotación de los recursos naturales y de los conflictos socio-ambientales en territorios con antigua presencia guerrillera. Desde cierta perspectiva el pos-acuerdo puede ser visto como una ventana de oportunidad para que las empresas extractivas entren a regiones que durante años les estaban vedadas debido a las condiciones del conflicto armado. En palabras de Boaventura de Souza Santos, al no haber presencia guerrillera estos serán "territorio[s]libre[s] para las multinacionales de la minería y de la agricultura industrial [...] sale la guerra y entra la minería, y entra la expulsión"t46. Lo anterior es muy bien entendido por la industria petrolera, como lo explica J.C. Echeverry expresidente de Ecopetrol:

Con la paz esperaríamos tener la posibilidad de entrar a Caquetá mucho más fuerte, a Putumayo, a Catatumbo, sitios donde antes era difícil acceder. La paz nos debe permitir no solamente a Ecopetrol, sino a todas las petroleras del país, generando desarrollo en las regiones, sacar más petróleo ${ }^{47}$.

Se desprende que el contexto de pos-acuerdo será un nuevo reto para la preservación y conservación del ambiente y para las comunidades locales. Frente a esta situación el caso del conflicto socio-ambiental en el BSJ puede dar algunas pistas

45 Entrevista 9. Miembro de la AASLBS. Septiembre de 2016.

46 Santos, 2015.

47 Periódico El Espectador. "La paz nos va a permitir sacar más petróleo en zonas vedadas" [En línea].Bogotá: El Espectador: 14 de abril de 2016 <http://www.elespectador.com/noticias/economia/ paz-nos-va-permitir-sacar-mas-petroleo-de-zonas-vedadas-articulo-627058 >. [18 de mayo de 2018] 
de lo que podría suceder en territorios "ricos en recursos naturales" y con antigua presencia guerrillera. Este paralelo se realiza en la medida en que el BSJ podría considerarse como un laboratorio del pos-acuerdo, pues luego del repliegue del F-32 -FARC-EP y de la desmovilización del BSP-AUC en 2008, esta zona quedó sin presencia de grupos armados ilegales y bajo el dominio territorial de la Fuerza Pública y del Estado Colombiano ${ }^{48}$. Lo que sucedió en este caso fue que inmediatamente después del retiro de los actores armados ilegales, el capital privado internacional a través de GTE intentó entrar a la región, concordando con lo planteado por el presidente de Ecopetrol. Frente a esta arremetida y ante la ausencia en la zona de actores armados ilegales, la comunidad local decidió organizarse en torno a la AASL para impedir las actividades extractivistas en su territorio. En un principio la organización confío en los procedimientos legales y judiciales para impedir este proceso y procuró concertar una solución pacífica. Sin embargo frente la negativa de GTE para negociar y frenar las actividades exploratorias, y ante el desgaste y la imposibilidad de concretar soluciones mediante los procedimientos legales, la comunidad recurrió a la quema de maquinaria y a las amenazas a trabajadores. Simplificando en exceso, podría decirse que ante el desgaste de los arreglos institucionales y legales, y frente a la ausencia de actores armados ilegales en la zona, la comunidad se vio obligada a hacer uso de la misma estrategia que durante años blindó a la región: la violencia.

Esperemos que este tipo de conflictos, que ya se están presentando en distintas zonas del país, puedan resolverse sin acudir a la violencia, aunque el alto número de líderes sociales y de defensores del medioambiente y de la tierra asesinados podría indicar lo contrario ${ }^{49}$.

\section{Conclusiones}

Con el objetivo de comprender los procesos políticos del conflicto socio-ambiental conjuntamente con las dinámicas territoriales del Bloque San Juan se ha buscado en este trabajo elaborar un diálogo, hasta donde sabemos, original, entre el giro territorial, la estructura de oportunidades políticas y la sociología pragmática. Este ejercicio consistió en tomar los principales presupuestos de cada corriente y tender puentes para su comunicación con el fin de esbozar un nuevo enfoque teórico para el análisis del conflicto. Se concluyó que las nociones de restricciones y oportunidades políticas, repertorios de acción, frames-territoriales, contextos de experiencia y procesos de apropiación del espacio ((re)(des)territorialización), son elementos constitutivos del conflicto, pues cada uno, así como sus relaciones, resultaron fundamentales dentro de

48 Situación en la que muchos territorios se encuentran. Claro está que otras regiones tendrán que enfrentar dificultades diferentes, pues ante la ausencia de las FARC-EP y del Estado, diversos grupos armados al margen de la ley (ELN, disidencias de las FARC, grupos neo-paramilitares, delincuencia común) ya están intentando suplir el vacío que deja esta guerrilla.

49 Según Global Witness entre 2002 y 2015 han sido reportados 970 casos (amplio sub-registro) de los cuales el 77\% han sucedido en América Latina. Los países más peligrosos para ejercer estas actividades (donde sucedieron más asesinatos per cápita) son: 1) Honduras (128), Colombia (108) y Brasil (527). Global Witness, 2017. 
la evolución de la confrontación. Sobre esta perspectiva, el conflicto se entendió como un entramado de relaciones entre esos elementos constitutivos y diversos agentes directa e indirectamente involucrados, motivo por el cual tales elementos no deben analizarse separadamente como procesos aislados y mono-causales, sino que deben entenderse dentro de esa compleja red de relaciones interdependientes en donde una mudanza en alguno repercute en los otros procesos. Esta aproximación teórica resulta interesante y atractiva para analizar conflictos políticos entre territorialidades superpuestas que se configuran dentro del campo ambiental (conflictos socio-ambientales), sobre todo en contextos espacio-temporales tan particulares como el del BSJ, en la medida en que se relacionan conjuntamente las dinámicas territoriales y sociopolíticas del conflicto. A continuación se presentan algunas conclusiones sobre cada uno de estos elementos constitutivos del conflicto en el BSJ: 1) restricciones y oportunidades políticas; 2 ) contextos de experiencia y procesos de apropiación del espacio, 3) repertorios de acción, y 4) frames-territoriales.

1) Sobre las restricciones y oportunidades políticas, debe hacerse hincapié en que en este caso las restricciones relacionadas con el conflicto armado desempeñaron un papel principal, pues la presión de los grupos armados modificó drásticamente la evolución del conflicto socio-ambiental. En un principio, cuando las FARC-EP eran el único grupo armado presente en la zona, a pesar de ciertas presiones, la ONG-AASL se mantuvo activa e incluso alcanzó su objetivo principal al negociar las condiciones de inserción con Ecopetrol. Luego, con el escalonamiento del conflicto armado por la arremetida paramilitar, la organización comunitaria se desarticula durante varios años debido a los asesinatos, amenazas y desplazamientos forzados, contexto de experiencia colectivo que marcó intensamente los demás elementos constitutivos del conflicto. Finalmente, después del des-escalonamiento del conflicto a partir de 2008 y debido a las lógicas territoriales de éste (que llevaron a que el desplazamiento forzado se realizara sobre la modalidad de abandono forzado) los habitantes del BSJ iniciaron un particular proceso de re-territorialización, fenómeno que de nuevo modificó drásticamente los elementos constitutivos del conflicto, entre estos la utilización de ciertos repertorios de acción que resultarían inviables sobre las anteriores condiciones de guerra (grandes movilizaciones, paro y quema de maquinaria). Ahora bien, esto no debe llevar a la conclusión de que la evolución del conflicto en el BSJ se vio determinada por las lógicas de la guerra, más bien a que éstas restringieron sus posibilidades.

2) Respecto a los contextos de experiencia, se deben realizar los siguientes comentarios. Dos tipos de contextos de experiencia resultaron esenciales en el recorrer del conflicto socio-ambiental: i) contextos de experiencia colectivos ligados a procesos de territorialización. ii) contextos de experiencia individuales de algunos líderes de la zona. ) Los procesos de apropiación del espacio por parte de la comunidad fueron uno de los factores que más influyeron en la evolución del conflicto. Dentro de éstos, aquellos ligados a las geografías del terror de Oslender ${ }^{50}$ fueron los que más impacto 
tuvieron, pudiendo ser procesos de des-territorialización a través de la instauración de paisajes del terror, de restricciones en la movilidad, o del desplazamiento forzado, o por el contrario procesos de re-territorialización como el retorno de los habitantes o la férrea decisión de no permitir otro desplazamiento sin importar las consecuencias. ii) Los contextos de experiencia individuales de algunos líderes también fueron primordiales dentro del conflicto y probablemente sin la presencia de alguno de éstos la confrontación hubiera tomado otro rumbo. Sin embargo, al tener en cuenta la influencia de estos individuos se debe tener cuidado de caer en personalismos o heroísmos, o en exagerar o exaltar su participación, pues el producto seria un simple "relato heroico" y no permitiría el entendimiento sociológico, político y geográfico.

Además, se debe mencionar otro contexto de experiencia de escala global que ha influido profundamente en la confrontación, y continuará haciéndolo en el futuro: el precio internacional del petróleo, definido por factores de escala mundial que regulan la oferta y la demanda, y que obedecen a relaciones geopolíticas internacionales. A pesar de que GTE paró las actividades exploratorias debido a las presiones y acciones de la comunidad, y a las restricciones impuestas por Corpoamazonia y la ANH, se debe recordar que para la época (enero de 2105) la crisis del crudo ya había iniciado y el precio internacional del petróleo rondaba los 50\$ USD por barril. Esta crisis afectó drásticamente las actividades de la industria petrolera colombiana, especialmente las relacionadas con la exploración. Según la Cámara Colombiana de Bienes y Servicios Petroleros (CAMPETROL), precisamente en el 2015, las actividades de exploración de crudo "disminuyeron un $80 \% "$ " 1 . De esta forma, el retiro de la empresa a inicios de ese año y su negativa a nuevas tentativas de inserción debe conectarse a su vez con dinámicas relacionadas a la caída del precio internacional del crudo.

3) Alrededor de los repertorios de acción surgen las siguientes consideraciones. La elección y efectividad de repertorios de acción, más que responder a una elección racional del grupo movilizado, corresponde a un entramado de relaciones entre los diversos actores involucrados, los imaginarios históricos colectivos de lucha y los demás elementos constitutivos del conflicto. Sobre esta óptica la quema de maquinaria, más que una elección calculada y racional de la comunidad, se debe entender como el acumulado de oportunidades y restricciones políticas, contextos de experiencia colectivos e individuales, y procesos territoriales, entre los que se destacan: el agotamiento e ineficacia de los demás repertorios, el desgaste físico, mental y económico de dos meses de paro y la imposibilidad de una negociación debido a la incompatibilidad de frames-territoriales enfrentados. Vale la pena ahondar en este último punto, pues al analizar este conflicto se observa que en los procesos de elección y de efectividad de repertorios de acción, la afinidad y compatibilidad entre los frames-territoriales enfrentados estipula fuertemente su evolución. En un primer momento cuando las territorialidades enfrentadas compartían el mismo fin (extracción de petróleo) y

51 Revista Semana. "Los Beverly pobres" [En Línea]. Bogotá: Publicaciones Semana: 26 de marzo de 2016 <http://www.semana.com/nacion/articulo/regalias-y-precio-del-petroleo-crisis-economica-en-municipios/466554>. [17 de mayo de 2018] 
sólo discordaban en la forma (condiciones), los repertorios de acción "tradicionales", jurídicos y no-violentos (sobre todo reuniones) resultaron ser los más efectivos. Ya cuando los frames-territoriales enfrentados son incompatibles, el diálogo a través de los repertorios "tradicionales", legales y pacíficos se agota y entran en juego repertorios violentos como los chantajes, engaños, amenazas, riñas y quemas.

4) Además de la anterior idea, sobre los frames-territoriales, también debe decirse que el término fue acuñado con el fin de superar los impasses que a menudo presentan ciertos usos de la noción de frames, que al tomarlos como meros recursos simbólicos para alcanzar objetivos concretos dejan de lado las dimensiones territoriales e históricas del conflicto. Lamentablemente, por falta de espacio y alcance no se analizó a fondo el proceso de configuración del frame-territorial de la "nueva y buena consciencia ambiental" en el BSJ (objeto de un próximo artículo) ${ }^{52}$. Empero, resulta pertinente presentar la siguiente conclusión y avance analítico: con la (re) configuración del frame-territorial de la "nueva y buena consciencia ambiental", el conflicto sufrió una transformación drástica, pues pasó de ser una disputa por las condiciones de explotación de los recursos petroleros y las disposiciones legales sobre ese derecho, a una lucha por los significados, representaciones y apropiaciones sociales y culturales del territorio. Se volvió un conflicto de territorialidades superpuestas entre regímenes de naturaleza contradictorios. Además, durante el proceso de (re)configuración de este frame-territorial y las formas de apropiación del espacio que conlleva (prácticas de producción agroforestales, sustitución de cultivos de usos ilícito, regulación de cacería, pesca y tala, cuidado de las fuentes de agua, etc.), se demuestra lo expuesto por Woortman ${ }^{53}$ cuando afirma que la trayectoria indígena-campesina no es lineal y que ciertas dinámicas que en principio parecerían que podrían llevarla a la modernidad, pueden impulsarla en la dirección opuesta: a la (re)construcción de la tradición En este caso la presión de las empresas petroleras, el conflicto armado y el desplazamiento de la población a las urbes, llevaron a un fenómeno contrario: un fuerte proceso de re-territorialización y apego a la tradición campesina- indígena.

\section{Bibliografía}

ACSELRAD, H. As práticas espaciais e o campo dos conflitos ambientais. In Acselrad. Conflitos ambientais no Brasil. Rio de Janeiro: Relume Dumará, 2004, p.13-36.

AGNEW, J., \& OSLENDER, U. Territorialidades superpuestas, Soberanía en Disputa: Lecciones empíricas desde América Latina. Tabula Rasa, 2010, No. 13, p. 191-213. BOURDIEU, P. Espaço social e espaço simbólico. In Bourdieu. Razões práticas: sobre a teoria da ação. Campinas: E.Papirus, 1996, p. 13-34.

52 Ver Azuero, 2017, Cap. 5.

53 1990, p. 16 Apud Salgado 2012, p. 198 
CEFAÏ, D. Diez propuestas para el estudio de las movilizaciones colectivas. Revista de Sociología, 2011, No. 26, p. 137-166.

CENTRO NACIONAL DE MEMORIA HISTÓRICA (CNMH). EL Placer: Mujeres, coca y guerra en el Bajo Putumayo. Bogotá: Taurus, 2012, p. 384.

CNMH. Petróleo, coca, despojo territorial y organzación social en Putumayo. Bogotá: CNMH, 2015, p. 309.

CHAVES, M. Conflictos territoriales o la política de la ubicación. Actores étnicos, re-etnizados y no étnicos en disputa por un territorio en el Putumayo. Territorio Y Cultura: Territorios De Conflicto Y Cambio Sociocultural. Manizales: Universidad de Caldas, 2002, p. 167-188.

DUARTE, E. Avance componente cartográfico. Asociación Ambiental El Salado de Los Loros, Mocoa: 2016, p. 12.

GLOBAL WITNESS Defender la tierra: Asesinatos globales de defensores/as de la tierra y el medio ambiente. Londres: Global Witness Limited, 2016, p. 62.

GONZÁLEZ, F., BOLÍVAR, I., \& VÁSQUEZ, T. Violencia politica en Colombia: de la nación fragmentada a la construcción del Estado. Bogotá: CINEP, 2002, p. 336.

HAESBAERT, R. Territorio e Multiterritorialidade. GEOgraphia, Niteroi, 2007, No. 17, p. $19-46$.

HARVEY, D. A condição pós-moderna. São Paulo: Loyola, 1992, p. 352.

MC ADAM, D., TARROW, S., \& TILLY, C. Para mapear o confronto político. Lua Nova, 2009, No. 76. P. 11-48.

OSLENDER, U. Comunidades negras y espacio en el pacífico colombiano: Hacia un giro geografico en el estudio de los movimientos sociales. Bogotá: ICANH. 2008a, p. 356.

OSLENDER, U. Geografías del terror: un marco de análisis para el estudio del terror. Scripta Nova. Revista Electrónica de Geografía y Ciencias Sociales. Barcelona: Universidad de Barcelona, 2008b, vol. XII, núm. 270, p. 144 -161.

PORTO-GONÇALVES, C.W. Da geografia às geo-grafias: um mundo em busca de novas territorialidades. In A. Ceceña, \& E. Sader, La guerra infinita: hegemonía y terror mundial. Buenos Aires: Clacso, 2002, p. 217-256.

RAMÍREZ, M. Entre el estado y la guerrilla : identidad y ciudadania en el movimiento de los campesinos cocaleros del Putumayo. Bogotá: ICANH, 2001, p. 350.

RIAÑO, P. Recuerdos metodológicos: El taller y la investigación etnográfica . Estudio sobre las culturas contemporáneas, Vol. 5, No. 10, 2000, p. 143-162.

SALGADO, H. El campesinado de la Amazonia colombiana: Construcción territorial, colonización forzada y resistencias. Montreal: Universidad de Montreal, 2012, p. 353. 
SANTOS, B. Un diálogo sobre los derechos humanos y la paz. VII Conferencia Latinoamericana y Caribeña de Ciencias Sociales "Transformaciones democráticas, justicia social y procesos de paz". Medellin; CLACSO, 2015.

SANTOS, M. Por uma geografia nova. São Paulo: Hucitec, 1978, p. 240.

TARROW, S. O poder em movimento. Petrópolis: Vozes, 2009, p. 143.

VÁSQUEZ, T., VARGAS, A., \& RESTREPO, J. Una vieja guerra en un nuevo contexto: Conflicto y territorio en el sur de Colombia. Bogotá: CINEP, 2011, p. 466.

WOORTMANN, K. 'Com parente nâo se neguceia' O Campesinato como ordem moral. Anuario Antropológico. Brasilia; Editora Universidade de Brasilia/Tempo Brasileiro, 1990, No. 87, p. 11-73.

ZIRAKZADEH, C. Social Movements in politics: A comparative study. Londres: Longman, 1997, p. 288.

(c) Copyright: Juan Azuero Melo, 2019

(c) Copyright: Scripta Nova, 2019

AZUERO MELO, Juan; Resistencia, petróleo y conflicto armado en la Amazonia Andina: análisis desde la geografía crítica y la sociología politica del conflicto socio-ambiental del Bloque San Juan, Barcelona: Universitat de Barcelona, 15 de mayo de 2019, vol. XXIII, $n^{\circ}$ 614. [ISSN: 1138-97] 